\title{
Mineralogy of Martian atmospheric dust inferred from thermal infrared spectra of aerosols
}

\author{
Victoria E. Hamilton \\ Hawaii Institute of Geophysics and Planetology, University of Hawaii, Honolulu, Hawaii, USA \\ Harry Y. McSween Jr. \\ Department of Earth and Planetary Sciences, University of Tennessee, Knoxville, Tennessee, USA \\ Bruce Hapke \\ Department of Geology and Planetary Sciences, University of Pittsburgh, Pittsburgh, Pennsylvania, USA \\ Received 24 May 2005; revised 29 July 2005; accepted 12 August 2005; published 7 December 2005.
}

[1] We have utilized optical constants derived from thermal infrared spectra acquired by the Mariner 9 Infrared Interferometer Spectrometer (M9 IRIS) and Mars Global Surveyor Thermal Emission Spectrometer (MGS TES), during periods of relatively high dust/low water ice opacity, to generate synthetic transmission and emission spectra of the atmospheric dust. Using libraries of transmission and emission spectra of common rockforming minerals and their alteration products, we applied a linear deconvolution algorithm to the spectra to model the dust mineralogy. Models of the M9 IRIS transmission data generally are of poor quality, and the mineralogical results of these fits are unlikely to be valid. Fits to the TES transmission spectrum and TES and IRIS emission spectra are of better quality and suggest that the dust mineralogy is dominated by framework silicates (feldspar and/or zeolite) with carbonate, sulfate, pyroxene, and olivine, identified near, but below, generalized detection limits. Evidence for phyllosilicates is not robust. Our results, combined with those from in situ measurements and other visible to infrared spectral studies, suggest that framework silicates (probably feldspar) dominate the dust mineralogy, with lesser amounts of olivine, pyroxene, amorphous material, hematite, and magnetite, and that the dust largely is the product of mechanical weathering of basaltic rocks with minor chemical alteration.

Citation: Hamilton, V. E., H. Y. McSween Jr., and B. Hapke (2005), Mineralogy of Martian atmospheric dust inferred from thermal infrared spectra of aerosols, J. Geophys. Res., 110, E12006, doi:10.1029/2005JE002501.

\section{Introduction}

[2] The earliest observers of Mars noted, in addition to its remarkable "redness", that "bright" and "dark" regions could be discerned on the planet. More quantitative observations of visible albedo and thermophysical properties, enabled by high spectral and spatial resolution telescopic and robotic exploration, have revealed that mobile sand and other coarse materials dominate the darker regions, whereas the brighter regions likely are dominated by fine particulates (e.g., dust). The surface dust presumably is the product of mechanical and/or chemical weathering of coarser surface materials circulated by regional and global dust storms [Pleskot and Miner, 1981; Christensen, 1988]. The coarse nature of materials in the dark regions makes it relatively easy to determine compositional information via remote spectroscopic methods. The nature of dusty materials, on the other hand, presents some significant challenges to the determination of their mineralogy. Although numerous

Copyright 2005 by the American Geophysical Union. 0148-0227/05/2005JE002501\$09.00 inferences have been made about the mineralogy of Martian surface dust from visible and near-infrared spectral observations (summarized by Bell [1996] and Bell et al. [2000]), direct determination has been hampered by spectral masking due to fine-grained ferric oxides. At thermal infrared wavelengths, scattering effects dominate observations of dust on the surface and, until recently [Bandfield and Smith, 2003], have complicated significantly the interpretation of the surface dust spectrum. Our limited understanding of the minerals that constitute the dust and surficial soils hampers our understanding of Martian weathering processes and conditions.

[3] The physical and/or chemical processes that produced the surface dust, and the environmental conditions under which these processes took place, determined its current mineralogy. Soils measured by the Viking landers originally were interpreted primarily as mixtures of clay minerals (Fe-bearing smectites) and $\mathrm{Fe}$ oxides formed by chemical weathering and cemented into duricrust by salts [Toulmin et al., 1977; Gooding, 1992]. Spectral features resulting from $\mathrm{Fe}^{3+}$ provide evidence for hematite, but features of crystalline silicates have not been confidently identified in 
visible and near-infrared spectral observations of dusty regions, leading to the suggestion that the soils largely are composed of chemically weathered, amorphous or poorly crystalline materials [e.g., Bell, 1996]. In contrast, Mars Pathfinder soil compositions commonly have been modeled as comminuted igneous rocks (mixtures of basalt and andesite) formed by mechanical weathering [Larsen et al., 2000; Morris et al., 2000; Wänke et al., 2001], and appear to contain a ferric pigment of poorly crystalline, nanometer-sized oxide particles dispersed within a silicate matrix [Bell et al., 2000], likely hematite [e.g., Morris et al., 1989; Bell et al., 1990]. This mixed ferric oxide-silicate composition also is characteristic of the atmospheric dust, based on its magnetic [Madsen et al., 1999; Goetz et al., 2005] and near-infrared spectral [Bell et al., 2000] properties. Specifically, results from the magnetic properties experiments on the Mars Exploration Rovers (MER) have been interpreted to indicate that the atmospheric dust contains magnetite as the primary magnetic phase and is the product of mechanical weathering of a basaltic protolith with simultaneous or subsequent oxidation [Goetz et al., 2005]. McSween and Keil [2000] estimated the chemical composition of the global dust from the least-cemented Viking soil and the Pathfinder soil with the smallest admixture of the local andesitic rock. They interpreted this dust composition as basalt weathered in an aqueous environment, producing poorly crystalline material similar to palagonite. Palagonitic tephra is the best analog for visible and near-infrared spectra of bright (dust covered) regions on Mars [Morris et al., 1990; Bell et al., 1993], although it is not a good thermal infrared spectral analogue [Hamilton and Morris, 2003]. Martian soils also may have experienced aeolian fractionations of dense oxide phases [McLennan, 2000]. Observations of a strong 3- 4 m hydrated mineral feature suggest the presence of $\mathrm{OH}$ and/or $\mathrm{H}_{2} \mathrm{O}$ in the dust [Houck et al., 1973; Bell and Crisp, 1993; Murchie et al., 1993], possibly in the form of clay minerals, palagonite, and hydrous carbonates, and analysis of reflectance spectra is consistent with up to 4 wt. $\% \mathrm{H}_{2} \mathrm{O}$ in Martian soils [Yen et al., 1998]. Bandfield and Smith [2003] produced shapes of thermal infrared spectra high albedo (dusty) Martian surfaces, and found that the spectra of these surfaces have features consistent with materials dominated by silicates. No single phase matches the surface dust spectrum uniquely, but features consistent with intermediate to calcic plagioclase and bound water (in unidentified phases) are dominant. A low $(\sim 2-5 \%)$ fraction of carbonate [Bandfield et al., 2003] or possibly hydrous iron sulfate [Lane et al., 2004] has been identified in this surface dust spectrum as well. Features consistent with mafic minerals, such as pyroxene and olivine, are lacking, although thermal infrared spectra of rocks ground into fine particulates may contain up to $30 \%$ mafic phases for which spectral features are not readily identified [Hamilton, 2003]. Bandfield and Smith [2003] infer that Martian surface dust is composed of both primary (e.g., plagioclase) and secondary (hydrous) minerals, with either a significant mechanical weathering explaining the prevalence of feldspar over alteration minerals (favored), or a physical mixture of chemically altered and unaltered materials. The $\mathrm{Fe}^{3+}$-bearing minerals that are so prominent in visible and near-infrared spectra are not detected in thermal infrared spectra of the surface dust, probably because they are present at low volumetric abundance and may occur as surficial stains on mineral grains.

[4] The atmospheric dust presumably is related to the surface dust and soils, representing the finest grained materials in surface sedimentary deposits. Federova et al. [2002] have reported an $\mathrm{OH}^{-}$stretching band near $2.7 \mu \mathrm{m}$ in aerosol spectra, although aerosol spectra described by Erard et al. [1994] and Kirkland et al. [1999] show no evidence of $3 \mu \mathrm{m}$ or $6 \mu \mathrm{m} \mathrm{OH}$ absorption features. In thermal infrared measurements, the atmospheric transmission contributes to the spectral radiance as much or more than the emission from surface materials. The composition of lofted surface dust may be estimated by analysis of the strong atmospheric transmission signature, which is dominated by absorptions in the $1250-800 \mathrm{~cm}^{-1}(\sim 8-12 \mu \mathrm{m})$ region [e.g., Hanel et al., 1972a, 1972b; Conrath et al., 1973; Hunt et al., 1973; Toon et al., 1977; Christensen et al., 1998]. These features are consistent with the presence of significant amounts of silicate materials, and studies using a variety of data sets have identified qualitative similarities in shape between the thermal infrared spectra of Martian atmospheric dust and the transmission spectra of sheet silicates [Hunt et al., 1973; Aronson and Emslie, 1975; Toon et al., 1977], palagonite [Roush et al., 1991; Clancy et al., 1995], olivine [Hugeunin, 1987], and feldspar [Aronson and Emslie, 1975; Grassi and Formisano, 2000]. Small concentrations of carbonate [Pollack et al., 1990; Lellouch et al., 2000] also have been suggested as components of the atmospheric dust from infrared data.

[5] We hope to place constraints on the composition of the atmospheric dust via a two-step process. First, using optical constants derived from MGS TES and M9 IRIS data acquired during periods of high dust opacity, we synthesize transmission and emission spectra of the Martian dust. Second, we perform a linear deconvolution analysis of these spectra to constrain the composition of the dust. The combination of spectra derived from optical constants with a quantitative analysis of the dust spectral shape yields an analytical approach for determining the dust composition that has not been applied to this problem previously.

\section{Methods}

[6] The radiance spectrum measured at an orbiting sensor is a complicated combination of signatures that include not only scattering from suspended aerosols, but also the transmission and absorption of both the incident light and light scattered by the surface, as well as light multiply scattered between the surface and atmosphere, and can be described by the following equation [Bandfield and Smith, 2003]:

$$
I_{o b s}(v)=\varepsilon(v) B\left[T_{\text {surf }}, v\right] e^{-\tau_{0}(v) / \mu}+\int_{0}^{\tau_{0}}\left(B[T(p), v] e^{-\tau(v, p) / \mu} d \tau .\right.
$$

In this equation, $I_{\mathrm{obs}}(v)$ is the measured radiance, $\varepsilon(v)$ is the emissivity of the surface, $B\left[T_{\text {surf }}, v\right]$ is the blackbody radiance as a function of surface temperature, $\mathrm{T}_{\text {surf }}, \tau(v, p)$ is the normal opacity profile as a function of wave number and pressure, and $\mu$ is the cosine of the emission angle. The first term accounts for emission from the surface and its 

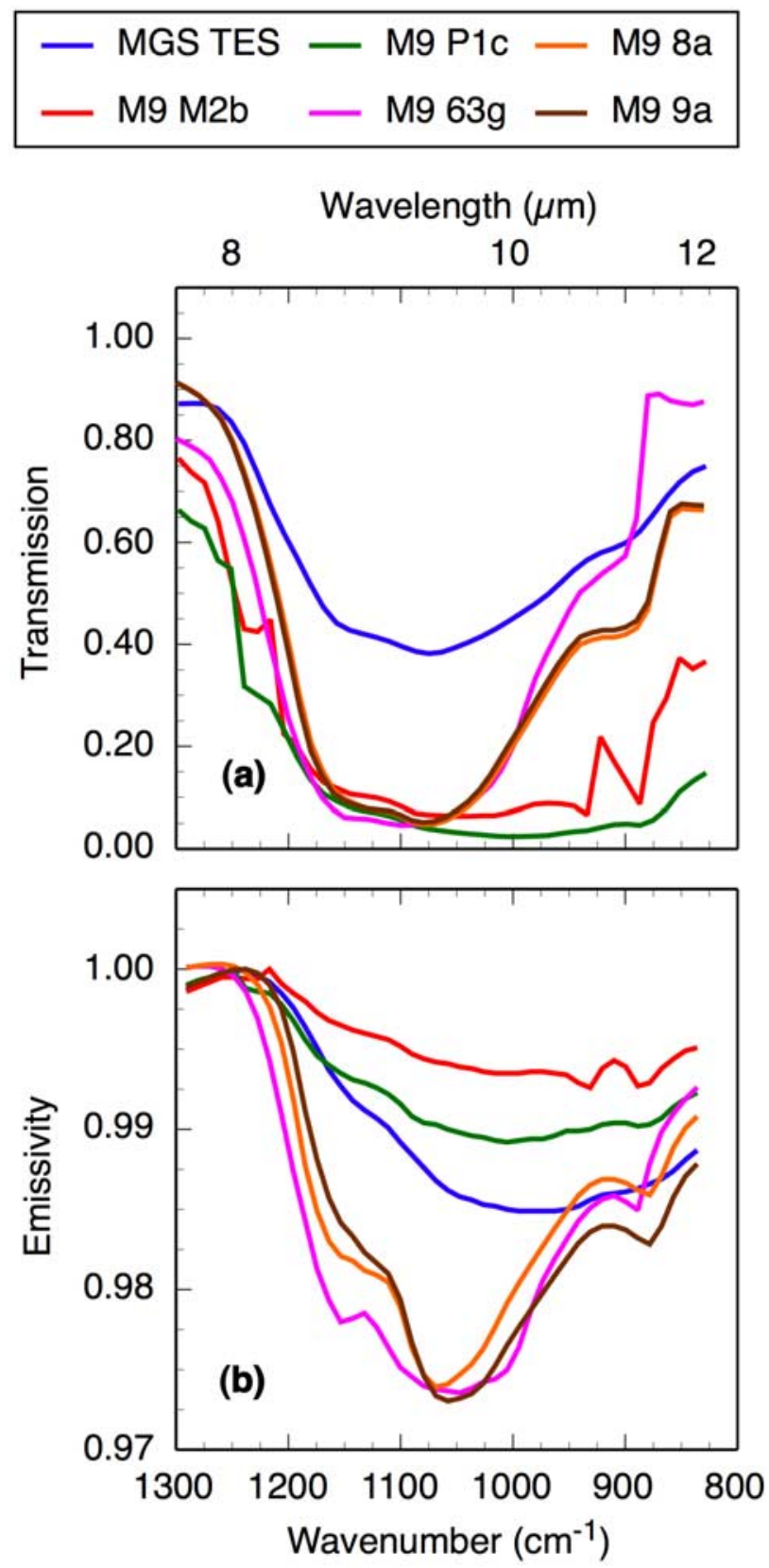

Figure 1. Atmospheric dust (a) transmission and (b) emission spectra calculated from optical constants retrieved from Mariner 9 IRIS and MGS TES data.

subsequent absorption by the atmosphere. The second term integral is taken through the atmosphere from the opacity at the spacecraft $(\tau=0)$ to the surface $\left(\tau=\tau_{0}\right)$ and $T(p)$ is the atmospheric temperature profile. This term accounts for radiation emitted by the atmosphere and suspended aerosols. Solar and thermal radiation reflected from the surface as well as secondary scattering are neglected in this equation, and surface radiation is considered to be diffuse. In addition, dust is assumed to be well mixed with the $\mathrm{CO}_{2}$ rich atmosphere and not stratified at any level. Interpreting the geologic components of the atmospheric dust requires some means of separating and solving for the radiance due only to the dust suspended in the atmosphere. One means of accomplishing this separation is to view a given area on the
Martian surface at different angles, and thus through different path lengths, as performed by Bandfield and Smith [2003] using TES data. However, these authors were interested in examining surface spectra derived from their separation, and did not convert their atmospheric opacities into effective infrared spectra. Another approach is to use optical constants derived from the measured spectra [Snook, 1999, 2002; Hansen, 2003] to calculate the effective transmission through (or emission from) the dust suspended in the atmosphere. This approach makes it possible to study the atmospheric dust spectrum in cases where multiple emission angle data are not available, such as with IRIS data.

[7] Snook [1999, 2002] inverted IRIS and TES infrared data using an iterative radiative transfer approach that solved for several parameters, including the spectral complex refractive indices and opacity of the aerosol dust (detailed description of the model is beyond the scope of this paper, but can be found in the cited works). We used Snook's baseline optical constants (cases P1c and M2b, her Tables 5.3 and 5.4) for our analysis of the Mariner 9 data [Snook, 1999] and the values for TES data were obtained from Snook [2002]. Independently, optical constants representing differing average surface and atmospheric temperature conditions (cases 63g, 8a, and 9a) have been derived from IRIS data by Hansen [2003] using a forward model, and also are included in our study. The optical constants need to be converted to infrared spectra so that they may be compared to available spectral libraries. We did this in two ways to obtain transmission and emission versions of the dust spectrum. We converted the modeled Martian refractive indices to equivalent transmittances (Figure 1a) using a Maxwell-Garnett effective medium model, described in detail by Hapke [1993]. This model uses the optical constants of the Martian dust to calculate the spectral absorption coefficient and transmittance that would be observed if we could analyze a $\mathrm{KBr}$ pellet containing Martian dust. We also used the refractive indices to calculate the Fresnel reflectivity and single scattering albedo of a large particle, which was then inserted into a radiative transfer algorithm [Hapke, 1996a, 1996b] to calculate the spectral emissivity of an infinitely thick layer of $800 \mu \mathrm{m}$ particles (Figure 1b). In this case, the highest value of each spectrum was assumed to correspond to the Christiansen feature and the spectra were normalized to unity at that wavelength.

[8] The calculated transmission and emission spectra were linearly deconvolved [e.g., Ramsey and Christensen, 1998] using transmission and emission spectra (respectively) obtained from the spectral libraries of Salisbury et al. [1991] and Christensen et al. [2000b]. The transmission endmember set we used contained $\sim 30$ minerals representing a range of minerals commonly associated with mafic igneous lithologies and their alteration products, including: feldspars, olivines, pyroxenes, zeolites, phyllosilicates, quartz, amphibole, goethite, gypsum, and calcite (Table 1). Although the linear deconvolution approach has not been utilized with transmission spectra (to our knowledge), linear mixing in transmission spectra of geologic materials has been demonstrated previously [e.g., Lyon et al., 1959; Omori, 1967]. Deconvolutions of the transmission spectra were limited to the $1275-830 \mathrm{~cm}^{-1}(\sim 7.8-12 \mu \mathrm{m})$ region to avoid spectral regions containing major atmospheric $\mathrm{H}_{2} \mathrm{O}$ 
Table 1. End-Members Used in Transmission Deconvolution

\begin{tabular}{|c|c|c|}
\hline Mineral Group & Mineral & Salisbury et al. [1991] Sample \\
\hline \multirow[t]{4}{*}{ Feldspar } & albite & $1 \mathrm{t}$ \\
\hline & anorthite & $1 \mathrm{t}$ \\
\hline & labradorite & $1 \mathrm{t}$ \\
\hline & microcline & $1 \mathrm{t}$ \\
\hline \multirow[t]{5}{*}{ Pyroxene } & augite & $1 \mathrm{t}$ \\
\hline & augite & $2 \mathrm{t}$ \\
\hline & diopside & $1 \mathrm{t}$ \\
\hline & enstatite & $1 \mathrm{t}$ \\
\hline & hypersthene & $1 \mathrm{t}$ \\
\hline \multirow{6}{*}{ Phyllosilicate } & biotite & $1 \mathrm{t}$ \\
\hline & illite & $1 \mathrm{t}$ \\
\hline & kaolinite & $2 \mathrm{t}$ \\
\hline & lizardite & $1 \mathrm{t}$ \\
\hline & montmorillonite & $3 \mathrm{t}$ \\
\hline & smectite & $1 \mathrm{t}$ \\
\hline \multirow{3}{*}{ Olivine } & olivine $\left(\mathrm{Fo}_{11}\right)$ & $1 \mathrm{t}$ \\
\hline & olivine $\left(\mathrm{Fo}_{66}\right)$ & $7 \mathrm{t}$ \\
\hline & olivine $\left(\mathrm{FO}_{92}\right)$ & $11 \mathrm{t}$ \\
\hline \multirow[t]{6}{*}{ Zeolite } & chabazite & $1 \mathrm{t}$ \\
\hline & natrolite & $1 \mathrm{t}$ \\
\hline & clinoptilolite & $1 \mathrm{t}$ \\
\hline & mordenite & $1 \mathrm{t}$ \\
\hline & prehnite & $1 \mathrm{t}$ \\
\hline & datolite & $1 \mathrm{t}$ \\
\hline \multirow[t]{5}{*}{ Other } & quartz & $1 \mathrm{t}$ \\
\hline & calcite & $2 \mathrm{t}$ \\
\hline & gypsum & $2 \mathrm{t}$ \\
\hline & goethite & $1 \mathrm{t}$ \\
\hline & hornblende & $2 \mathrm{t}$ \\
\hline
\end{tabular}

and $\mathrm{CO}_{2}$ absorptions, and because the lower wave number optical constants are less reliable. The spectra from the emission library included similar minerals (Table 2), most representing samples with particle sizes from $710-1000 \mu \mathrm{m}$, as well as end-members representing gaseous $\mathrm{CO}_{2}$, water vapor, and Mars surface dust. The atmospheric dust emission spectra were deconvolved over the wave number range of $1275-830 \mathrm{~cm}^{-1}$ to avoid major atmospheric $\mathrm{H}_{2} \mathrm{O}$ and $\mathrm{CO}_{2}$ absorptions as well as the lower wave number regions where the optical constants are less reliable.

[9] All synthetic IRIS spectra were resampled from their original $2 \mathrm{~cm}^{-1}$ sampling to the nominal $10 \mathrm{~cm}^{-1}$ spectral sampling of TES so that all of the modeling results would be directly comparable. Reducing the spectral resolution of the IRIS data in this way effectively filters it; the resampling reduces noise in the spectra, but it also will remove some spectral information as well, with narrow atmospheric gas features being the most strongly affected. Because we are interested in atmospheric dust mineralogy, not gases, and because most minerals do not have features narrower than $10-20 \mathrm{~cm}^{-1}$, we believe that this resampling is not likely to have a detrimental effect on our results. Further support comes from Hamilton and Christensen [2000] and Hamilton et al. [2001], who demonstrated that modeled mineral abundances obtained from laboratory data having $10 \mathrm{~cm}^{-1}$ sampling typically are within $5 \%$ of the abundances modeled from data having $2 \mathrm{~cm}^{-1}$ sampling. In these (and other) laboratory studies of deconvolution accuracy (measured vs. modeled abundance) at $2 \mathrm{~cm}^{-1}$ sampling, $5 \%$ is among the best accuracies observed, and we expect this value to be worse for remotely sensed data, which exhibit greater noise, include atmospheric components, and may be acquired at lower spectral resolution. Generalized uncertainties and detection limits associated with deconvolutions of the TES data set, for example, are on the order of $10-15 \%$ [e.g., Bandfield et al., 2000]. Therefore, once all of these factors are considered, we would expect any differences obtained from modeling the IRIS data at higher spectral resolution to be slight ( $\sim 5 \%)$, within the general uncertainties of the linear deconvolution as applied commonly to remote sensing data, and not necessarily representative of statistically significant improvements in the absolute accuracy of phase or abundance determinations. Lastly, the highly derived nature of the spectra we interpret here, which are models of optical constants, which themselves are derived from models of remote sensing data, leads us to assume that the general uncertainties in our study (for both IRIS and TES data) are higher than for direct interpretation of TES spectral data.

\section{Results}

[10] Deconvolution model fits to the synthetic TES and IRIS spectra are shown in Figures 2 and 3. The model fits to the IRIS transmission spectra generally are mediocre to poor (Figures $2 \mathrm{~b}-2 \mathrm{f}$ ) and indicate that the mineralogical information derived from the fits is not valid. We do not report the detailed deconvolution results of these samples, although we discuss the reasons for their elimination below. The model fit to the TES transmission spectrum (Figure 2a) is good, with a modeled mineralogy dominated by ( $\sim 70$ vol.\%) framework silicates, with gypsum, pyroxene, and olivine identified at or below 20 vol.\% (Table 3). The model fits to the dust emission spectra (Figure 3) generally are good. The modeled mineralogies of the emission spectra typically are dominated $(30-70 \%)$ by Martian surface dust

Table 2. End-Members Used in Emission Deconvolution

\begin{tabular}{|c|c|c|}
\hline Mineral Group & Mineral & Christensen et al. $[2000 \mathrm{~b}]$ Catalog ID \\
\hline \multirow[t]{4}{*}{ Feldspar } & albite & WAR-0235 \\
\hline & oligoclase & BUR-060 \\
\hline & labradorite & WAR-RGAND01 \\
\hline & maskelynite & ASU-7591 \\
\hline \multirow[t]{6}{*}{ Pyroxene } & augite & DSM-AUG01 \\
\hline & diopside & NMNH-R15161 \\
\hline & diopside & WAR-6474 \\
\hline & enstatite & HS-9.4B \\
\hline & bronzite & NMNH-93527 \\
\hline & pigeonite & $\mathrm{n} / \mathrm{a}^{\mathrm{a}}$ \\
\hline \multirow{3}{*}{ Olivine } & olivine (Fo10) & $\mathrm{n} / \mathrm{a}$ \\
\hline & olivine (Fo68) & $\mathrm{n} / \mathrm{a}$ \\
\hline & olivine (Fo91) & AZ-01 \\
\hline \multirow[t]{6}{*}{ Phyllosilicate } & illite & IMt-2 \\
\hline & kaolinite & KGa-1b \\
\hline & montmorillonite & STx-1/SCa-3 \\
\hline & Fe-smectite & SWa-1 \\
\hline & serpentine & BUR-1690/WAR-RGLIZ01 \\
\hline & nontronite & WAR-5108 \\
\hline \multirow[t]{3}{*}{ Zeolite } & chabazite tuff & $\mathrm{n} / \mathrm{a}^{\mathrm{a}}$ \\
\hline & clinoptilolite tuff & $\mathrm{n} / \mathrm{a}^{\mathrm{a}}$ \\
\hline & mordenite tuff & $\mathrm{n} / \mathrm{a}^{\mathrm{a}}$ \\
\hline \multirow{9}{*}{ Other } & quartz & BUR-4120 \\
\hline & anhydrite & ML-S9 \\
\hline & gypsum & ML-S8 \\
\hline & dolomite & $\mathrm{C} 17$ \\
\hline & calcite & ML-C9 \\
\hline & goethite & $\mathrm{n} / \mathrm{a}^{\mathrm{a}}$ \\
\hline & Mars surface dust & $\mathrm{n} / \mathrm{a}^{\mathrm{a}}$ \\
\hline & $\mathrm{CO}_{2}$ gas & $\mathrm{n} / \mathrm{a}^{\mathrm{a}}$ \\
\hline & $\mathrm{H}_{2} \mathrm{O}$ vapor & $\mathrm{n} / \mathrm{a}^{\mathrm{a}}$ \\
\hline
\end{tabular}

${ }^{\text {a}}$ Samples obtained from the following sources: Bandfield and Smith [2003]; Glotch et al. [2004]; Hamilton [2000]; Ruff [2004]. 

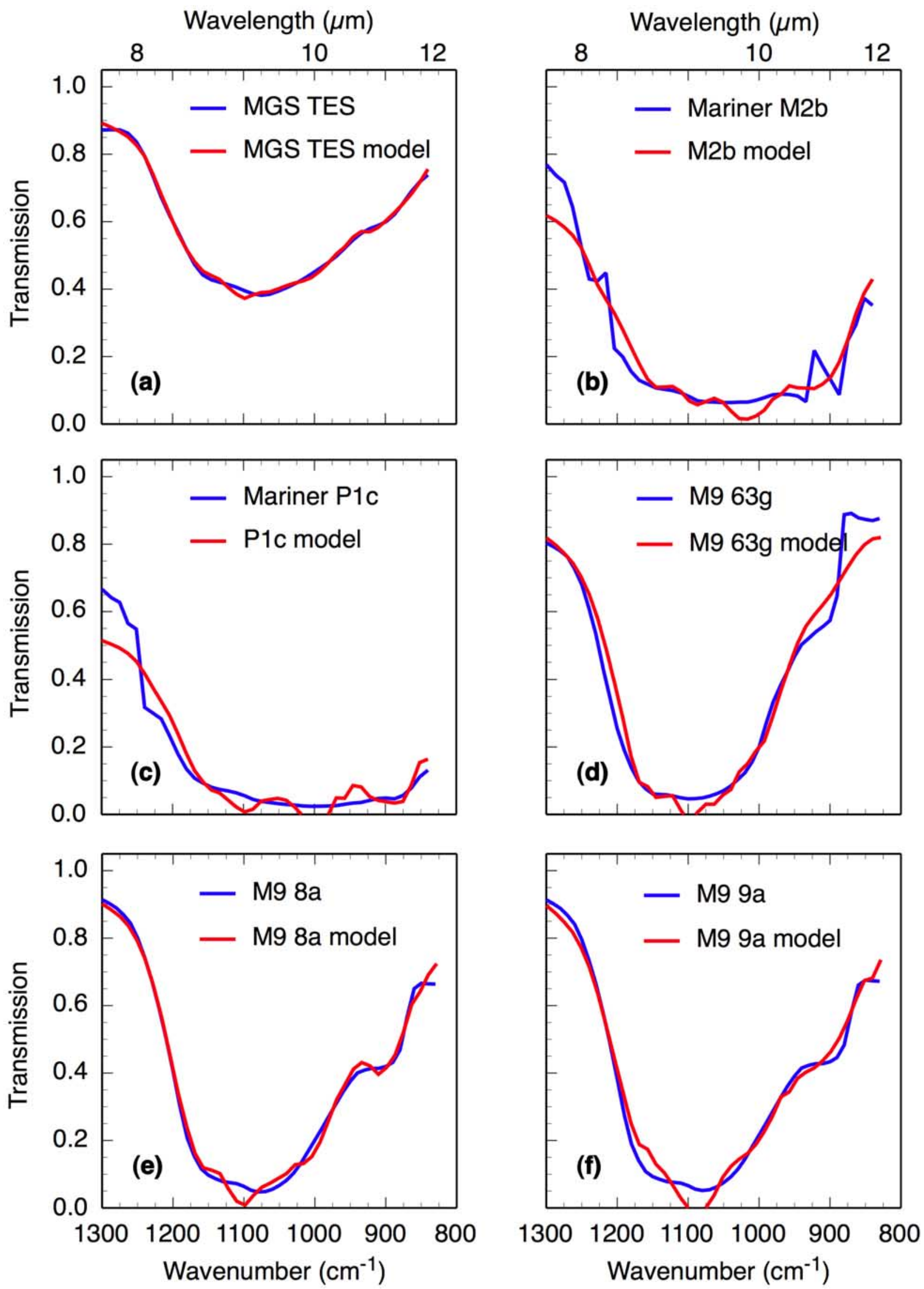

Figure 2. Best fit models to effective transmission spectra. 

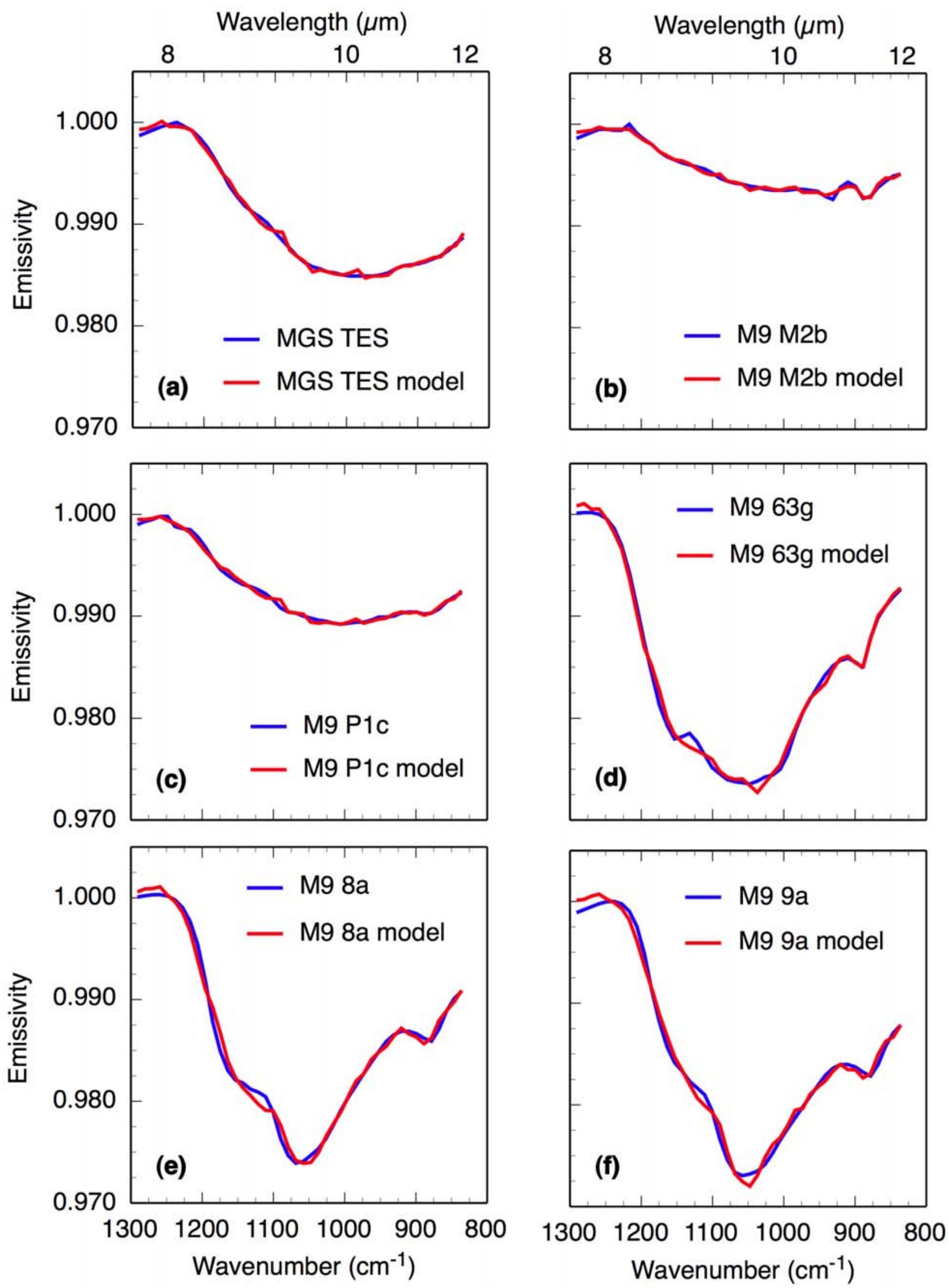

Figure 3. Best fit models to effective emission spectra. 
Table 3. Deconvolution Results ${ }^{\mathrm{a}}$

\begin{tabular}{|c|c|c|c|c|c|c|c|}
\hline Mineral Group & $\begin{array}{c}\text { TES } \\
\text { Transmission } \\
\text { vol. } \% \\
\end{array}$ & $\begin{array}{c}\text { TES } \\
\text { Emission } \\
\text { vol. } \% \\
\end{array}$ & $\begin{array}{c}\text { M9 M2b } \\
\text { Emission } \\
\text { vol. } \% \\
\end{array}$ & $\begin{array}{c}\text { M9 P1c } \\
\text { Emission } \\
\text { vol. } \% \\
\end{array}$ & $\begin{array}{c}\text { M9 63g } \\
\text { Emission } \\
\text { vol. } \% \\
\end{array}$ & $\begin{array}{c}\text { M9 8a } \\
\text { Emission } \\
\text { vol. } \% \\
\end{array}$ & $\begin{array}{c}\text { M9 9a } \\
\text { Emission } \\
\text { vol. \% } \\
\end{array}$ \\
\hline Zeolite & 35 & 0 & 0 & 10 & 30 & 15 & 0 \\
\hline Feldspar & 30 & 20 & 15 & 15 & 30 & 10 & 10 \\
\hline Pyroxene & 20 & 5 & 10 & 0 & 5 & 5 & 5 \\
\hline Sulfate & 15 & 0 & 0 & 0 & 5 & 0 & 0 \\
\hline Olivine & 5 & 0 & 0 & 0 & 0 & 0 & 0 \\
\hline Phyllosilicate & 0 & 10 & 10 & 0 & 20 & 20 & 25 \\
\hline Carbonate & 0 & 0 & 5 & 0 & 10 & 0 & 0 \\
\hline Goethite & 0 & 0 & 0 & 5 & 0 & 20 & 15 \\
\hline Surface dust & - & 70 & 60 & 60 & 0 & 30 & 40 \\
\hline
\end{tabular}

${ }^{\mathrm{a}}$ Values reported to nearest $5 \%$.

[Bandfield and Smith, 2003] and/or framework silicates (plagioclase and zeolite, $10-60 \%$ ), with phyllosilicates and goethite at $5-25 \%$, and several phases at or below $15 \%$ (Table 3 ).

[11] To evaluate the quality of deconvolution fits, we compare the measured and modeled spectra by visual inspection. The model spectra of the IRIS-derived dust transmission spectra in Figures $2 \mathrm{~b}-2 \mathrm{f}$ show significant deviations from the measured spectra, either failing to model accurately the measured features (e.g., features around $900 \mathrm{~cm}^{-1}$ in Figures $2 \mathrm{~b}$ and $2 \mathrm{~d}$ ) or introducing spectral features that are not present in the measured spectrum (e.g., features at $\sim 1100 \mathrm{~cm}^{-1}$ in Figures $2 \mathrm{~d}-2 \mathrm{f}$ ). The spectral fits in Figures $2 \mathrm{~d}-2 \mathrm{f}$ are the best of the IRIS subset; however, the major misfit around $\sim 1100 \mathrm{~cm}^{-1}$ is the result of significant modeled abundances of quartz (15$50 \%$ ), which are inconsistent with the known mineralogy of Mars, and the primary rationale for our not considering these deconvolution results further. Although it is tempting to compare the root mean square (RMS) errors from these models to each other or to those of previous models of Martian data, this is not a valid approach because the wavelength regions over which the deconvolutions were performed and the spectral contrasts of the spectra vary significantly. These differences affect the calculation of the RMS error value in such a way that makes it impossible to directly compare the values.

[12] The generally poor fits to the IRIS transmission spectra indicate a problem with either the end-member set used in the deconvolution or the spectra themselves. If the Martian spectra represent phases that are not included in the end-member library, the deconvolution algorithm cannot identify them and will utilize whatever available mineral spectra achieve the best numerical fit. Alternatively, the spectra may be flawed if the optical constants from which they are derived are inaccurate. One example pointing toward the latter case is the strong narrow spike in the IRIS M2b spectra near $900 \mathrm{~cm}^{-1}$, which is not characteristic of silicate mineral spectra. This spike could not have been introduced when we resampled the IRIS data to TES resolution, because resampling does not introduce features that are not already present, and would tend to have the effect of smoothing any pre-existing features. Apparent emissivity spectra (measured radiances converted to emission, without separation of surface and atmospheric signatures) acquired by TES and IRIS during Martian dust storms appear similar and we would expect that their optical constants and effective dust transmission spectra should appear similar as well. However, after optical constants are derived from these data and converted to effective transmission, dissimilarities (some resulting from differing approaches to the derivation of the optical constants) become apparent. Because the dust composition generally is uniform, and the synthesized TES transmission spectrum is modeled relatively well with the provided end-member minerals, we believe that there may be greater inaccuracies in the optical constants derived from IRIS spectra. The calculations of Snook [1999] and Hansen [2003] necessarily make several assumptions that affect the derived values of the optical constants. For example, in the absence of multiple emission angle observations, modeling of optical constants from IRIS data relies on assumptions about the particle size distribution that are derived from other estimates in the literature [Snook, 1999; Hansen, 2003]. We believe that uncertainties in this and other assumptions confound the derivation of optical constants from the IRIS data that are sufficiently accurate for the generation of robust dust transmission spectra. The TES optical constants, on the other hand, were derived using multiple emission angle measurements [Snook, 2002] and our modeled transmission spectrum appears more like the initial TES apparent emissivity spectrum. This spectrum yields a generally reasonable model fit and mineralogical result. The question then is raised as to whether or not the IRIS-derived emission spectra of the dust can be interpreted reliably if the optical constants contain inaccuracies. Interestingly, the IRIS emission spectra are better modeled than the transmission spectra. The mineral end-member sets used to deconvolve the transmission and emission data were selected to be very similar, so we doubt that the emission end-member set is more complete. Also, the model results from the IRIS emission spectra broadly are consistent with those of the TES transmission and emission spectra, which suggests that the IRIS emission spectra may be more reliable than the IRIS transmission spectra. The most likely explanation for the more reasonable fits to the synthesized IRIS emission spectra lies in the difference between the propagation of light transmitted through a sample versus the reflectivity of the surface of a sample. The light transmitted by a pellet is exponentially proportional to the imaginary part of the refractive index, whereas the emissivity of a coarse powder is determined by the reflectivity of the surface of a particle, which is roughly proportional to $\left[(\mathrm{n}-1)^{2}+\mathrm{k}^{2}\right] /(\mathrm{n}+1)^{2}+$ $\mathrm{k}^{2}$, where $\mathrm{n}$ and $\mathrm{k}$ are the real and imaginary components, respectively, of the refractive index. Hence transmission intrinsically is more sensitive to weaker spectral features 
than emissivity, and errors in the optical constants will be enhanced in our effective transmission spectra relative to our effective emission spectra.

\section{Discussion}

[13] Our data support the idea that framework silicates, such as feldspar, dominate the atmospheric dust. Intermediate plagioclase $\left(\sim \mathrm{An}_{30-70}\right)$ is the feldspar composition used in the best fits to the TES and IRIS emission spectra and the TES transmission spectrum. This compositional range compares favorably to feldspar compositions for global surface units calculated from TES spectral deconvolutions $\left(\mathrm{An}_{54-69}\right)$ [Hamilton et al., 2001] and for analyzed plagioclase in Martian basaltic meteorites $\left(\mathrm{An}_{45-60}\right)$ [McSween and Treiman, 1998]. The similarity in our deconvolved plagioclase composition with that of plausible source rocks lends credibility to the conclusion that the dust contains significant amounts of plagioclase. Differences in modeled feldspar abundance between the transmission ( $\sim 30 \%)$ and emission (15\% on average) spectra is derived largely from the inclusion of the TES-derived surface dust spectrum as an end-member in the emission deconvolutions and its use in the best fit for five out of six emission spectra. As described above, this spectrum represents a fine particulate surface suggested to be dominated by features attributable to framework silicates [Bandfield and Smith, 2003], and thus is consistent with a high total abundance of framework silicate in the emission spectra and the high total abundance derived from the transmission spectrum (there is no surface dust transmission spectrum in that endmember set).

[14] Because of their chemical and structural similarities, the thermal infrared spectra of fine particulate zeolites and feldspars are quite similar, and Ruff [2004] has suggested that the Martian surface dust may contain zeolite. Zeolites, like feldspars, are framework silicates and may be described loosely as hydrated feldspars. Our model results (Table 3) include both feldspar (all cases) and zeolite (four out of seven cases). Because of possible spectral ambiguity at fine particle sizes, Bandfield and Smith [2003] considered the possibility of zeolites as a component of the surface dust, but do not favor them because they have not been identified in Martian meteorites and because of the global lack of observed phyllosilicates and K-feldspar (minerals that commonly are present in the environments where zeolites form) in recent, high resolution remote sensing data sets [e.g., Christensen et al., 2001a; Bibring et al., 2005].

[15] Sulfate (gypsum) is modeled at low abundances in two cases, which is consistent with the presence of sulfur measured in soils at the Viking (7.9 wt. \% $\mathrm{SO}_{3}$ ) [Clark et al., 1982], Mars Pathfinder (6.8 wt.\% $\mathrm{SO}_{3}$ ) [Wänke et al., 2001], and Mars Exploration Rover (MER) [Gellert et al., 2004; Rieder et al., 2004] sites. Sulfates in soils on Mars have been predicted, based on thermodynamic stability considerations [Clark and Van Hart, 1981; Catling, 1999] and their occurrence as alteration products in Martian meteorites [Gooding, 1992]. Epsomite, rather than gypsum, has been suggested to be the dominant sulfate, based on a strong correlation between measured $\mathrm{Mg}$ and $\mathrm{S}$ in soils [Clark, 1993; Wänke et al., 2001]. Gypsum, kieserite, and one or more polyhydrated sulfates have been identified tentatively on the Martian surface by the Mars Express mission [Gendrin et al., 2005]. Gypsum and anhydrite occur as secondary minerals in Martian meteorites [Bridges et al., 2001] and the primary sulfate minerals identified in Terra Meridiani include jarosite [Klingelhöfer, 2004] and other Ca-Mg sulfates [Christensen et al., 2004]. Our detection of gypsum in dust is near to below general TES detection limits and although we cannot say confidently that it is present (it is not modeled in a majority of our spectra), it is consistent with other observations and may represent a sulfate phase in the atmospheric dust.

[16] Hydrated and hydroxylated phases (phyllosilicates and goethite) are identified in several models. Phyllosilicates are identified above general detection limits at abundances of $20-25 \%$ in three cases, and goethite is identified at $15-20 \%$ in two cases. The highest abundances of both phases all were identified in the emission spectra generated from the Hansen optical constants. Although phyllosilicates have been suggested previously as components of the Martian dust (see above), and goethite has been tentatively identified in various forms in Martian dust and rocks [Moroz et al., 1990; Bell et al., 2000; Kirkland and Herr, 2000; Morris and Klingelhöfer, 2005] or inferred from the presence of other mineralogies [Glotch et al., 2004], our relatively high modeled abundances are inconsistent with orbital and in situ observations that should have little difficulty identifying these phases if they are present in the large quantities implied here [Bell, 1996; Bell et al., 2000; Christensen et al., 2001a; Gellert et al., 2004; Bibring et al., 2005; Yen et al., 2005]. Ambiguities in distinguishing between the infrared spectra of coarse particulate zeolites, glasses, and phyllosilicates have been proposed and/or characterized [Bandfield et al., 2000; Wyatt and McSween, 2002; Ruff, 2004; Koeppen and Hamilton, 2005]. Therefore we have low confidence that the phyllosilicate identifications are reliable and distinguishable from other phases, particularly glasses, which were not included in our endmember sets. There is greater support for goethite on Mars, although we believe the relatively large abundances implied in two models here are suspect.

[17] There are several phases for whose presence our data do not or cannot show strong evidence. Only two of our seven deconvolutions identified carbonates in the atmospheric dust, and then only at $5-10 \%$. However, this is not necessarily unexpected as the strongest, broadest fundamental absorptions of carbonates are outside the wavelength range included in our deconvolutions. For example, the low $(\sim 2-5 \%)$ abundance of carbonate identified in surface dust by Bandfield et al. [2003] was identified using the $\nu_{3}$ fundamental feature $\left(\sim 1525 \mathrm{~cm}^{-1}\right)$, which is emphasized by the volume scattering that occurs in the surface dust. Our results generally do not show evidence for abundant olivine or pyroxene in the atmospheric dust. This result may indicate that the parent material contained low abundances of these phases or that they have been weathered away preferentially. We favor the former interpretation, as independent observations from MER provide evidence for olivine and pyroxene in the dust [Goetz et al., 2005]. Fundamental vibrational modes of Fe-oxides (such as hematite and magnetite) are located in the thermal infrared at relatively low wave numbers $\left(<\sim 650 \mathrm{~cm}^{-1}\right)$. Such features resulting from the presence of crystalline hematite on the 
Martian surface were identified from orbit using TES data [Christensen et al., 2000a, 2001b; Glotch and Christensen, 2005] and have been investigated subsequently in the Meridiani Planum region using the Miniature Thermal Emission Spectrometer (MiniTES) [Christensen et al., 2004] onboard the Opportunity rover. Magnetite is the dominant magnetic phase in the airborne dust measured at the MER landing sites, and is inferred to be a component of virtually all dust particles (which seem to be composites) [Goetz et al., 2005]. Despite these oxide identifications and the strong evidence in visible and near infrared spectral data for the presence of nanophase hematite (summarized by Bell [1996]), because the optical constants at these longer wavelengths are less reliable and were not included in our analysis, we are unable to infer the mineralogy or abundance of oxides in our atmospheric dust spectra. However, we note that thermal infrared apparent emissivity and brightness temperature spectra of the Martian dust, which typically are dominated by atmospheric transmission, do not show strong oxide features at long wavelengths, suggesting that the absolute volumetric abundances of such phases are relatively low [e.g., Hunt et al., 1973; Toon et al., 1977; Smith et al., 2000; Wolff and Clancy, 2003].

[18] Chemical analyses of Martian soils have been used to derive the chemistry of the global dust [McSween and Keil, 2000]. The dust composition cannot be rationalized only as mixtures of framework silicates with ferric oxides, so other components (mafic minerals and/or poorly crystalline phases) must be present. Because transmission spectra of volcanic glass and palagonite were not included in our endmember set, we cannot determine whether or not they might further improve the model fits to the spectra (e.g., by substituting for and reducing the modeled abundances of zeolite).

\section{Conclusions}

[19] The dominant phases identified here in the atmospheric dust are the framework silicates plagioclase feldspar and zeolite. Lesser, but significant, amounts of phyllosilicates and goethite were identified in some of our models, but we have low confidence in their identification (phyllosilicates) or abundance (goethite) because there is a lack of strong supporting evidence from independent measurements. Pyroxene, carbonate, sulfate, and olivine are identified, mostly at or below generalized detection limits. However, there is evidence for these latter phases in other data sets, and framework silicates alone cannot explain the spectral or chemical properties of the dust. Other phases must also be present, such as the oxides (hematite and magnetite) that provide the dust with its color and magnetic properties. Taking all of the visible, infrared, and in situ observations into consideration, it seems plausible to suggest that framework silicates (probably dominated by feldspar), with lesser amounts of olivine, pyroxene, amorphous material, hematite, and magnetite (the latter two possibly as coatings), make up the atmospheric dust and that the dust largely is the product of mechanical weathering of basaltic rocks with minor chemical alteration. If there has not been substantial aqueous alteration of the dust, as seems possible, the higher abundances of plagioclase relative to mafic phases also is consistent with the globally distributed, feldspar-rich basaltic compositions observed from orbit and in situ [e.g., Bandfield et al., 2000; McSween et al., 2004].

[20] Our framework silicate-dominated mineralogy is most consistent with the results of Aronson and Emslie [1975] for the atmospheric dust and Bandfield and Smith [2003] and Christensen et al. [2004] for the surface dust. The latter two studies offer some reassurance that the TES and MiniTES data sets are yielding consistent results regardless of the analytical approach. This consistency also provides support for the reliability of the optical constants derived from TES data in particular, for which additional constraints on measurement conditions can be acquired from the data rather than assumed. Several enhancements to the derivation of the TES optical constants will serve to improve them even further [Snook, 2002]. Hopefully, models of dust optical constants derived from past, current, and future thermal infrared observations will continue to advance, and future derivations of optical constants will permit additional refinement of the composition of Mars' globally distributed dust.

[21] Acknowledgments. We would like to thank Kelly Snook and Josh Bandfield for numerous helpful discussions on the use of optical constants for this work. Tim Glotch provided the goethite emission spectrum, and Steve Ruff provided the zeolite emission spectra. We thank Gary Hansen and an anonymous reviewer for their reviews, which led to several additions and clarifications. Gary Hansen kindly provided us with his Mariner 9 optical constants, originally labeled as marsdr63g, marsdrm8a, and marsdrm9a, shortened here to $63 \mathrm{~g}, 8 \mathrm{a}$, and 9a. The NASA Mars Data Analysis (H.Y.M., V.E.H.) and Geology and Geophysics (B.H.) Programs supported this investigation. This is HIGP publication 1401 and SOEST publication 6636 .

\section{References}

Aronson, J. R., and A. G. Emslie (1975), Composition of the Martian dust as derived by infrared spectroscopy from Mariner 9, J. Geophys. Res., 80, 4925-4931.

Bandfield, J. L., and M. D. Smith (2003), Multiple emission angle surfaceatmosphere separations of Thermal Emission Spectrometer data, Icarus, $161,47-65$

Bandfield, J. L., V. E. Hamilton, and P. R. Christensen (2000), A global view of Martian surface compositions from MGS-TES, Science, 287, $1626-1630$.

Bandfield, J. L., T. D. Glotch, and P. R. Christensen (2003), Spectroscopic identification of carbonate minerals in the Martian dust, Science, 301, $1084-1087$.

Bell, J. F., III (1996), Iron, sulfate, carbonate, and hydrated minerals on Mars, in Mineral Spectroscopy: A Tribute to Roger G. Burns, edited by M. D. Dyar et al., Spec. Publ. Geochem. Soc., 5, 359-380.

Bell, J. F., III, and D. Crisp (1993), Groundbased imaging spectroscopy of Mars in the near-infrared: Preliminary results, Icarus, 104, 2-19.

Bell, J. F., III, T. B. McCord, and P. D. Owensby (1990), Observational evidence of crystalline iron oxides on Mars, J. Geophys. Res., 95, $14,447-14,461$.

Bell, J. F., III, R. V. Morris, and J. B. Adams (1993), Thermally altered palagonitic tephra: A spectral and process analog to the soils and dust of Mars, J. Geophys. Res., 98, 3373-3385.

Bell, J. F., III, et al. (2000), Mineralogic and compositional properties of Martian soil and dust: Results from Mars Pathfinder, J. Geophys. Res., $105,1721-1755$.

Bibring, J.-P., Y. Langevin, A. Gendrin, B. Gondet, F. Poulet, M. Berthe, A. Soufflot, R. E. Arvidson, N. Mangold, J. Mustard, P. Drossart, and the OMEGA team (2005), Mars surface diversity as revealed by the OMEGA/Mars Express observations, Science, 307, 1576-1581.

Bridges, J. C., D. C. Catling, J. M. Saxton, T. D. Swindle, I. C. Lyon, and M. M. Grady (2001), Alteration assemblages in Martian meteorites: Implications for near-surface processes, Space Sci. Rev., 96, 365-392.

Catling, D. C. (1999), A chemical model for evaporites on early Mars: Possible sedimentary tracers of the early climate and implications for exploration, J. Geophys. Res., 104, 16,453-16,469.

Christensen, P. R. (1988), Global albedo variations on Mars: Implications for active aeolian transport, deposition, and erosion, J. Geophys. Res., 93, $7611-7624$. 
Christensen, P. R., et al. (1998), Results from the Mars Global Surveyor Thermal Emission Spectrometer investigation, Science, 279, 1692 1698

Christensen, P. R., et al. (2000a), Detection of crystalline hematite mineralization on Mars by the Thermal Emission Spectrometer: Evidence for near-surface water, J. Geophys. Res., 105, 9623-9642.

Christensen, P. R., J. L. Bandfield, V. E. Hamilton, D. A. Howard, M. D. Lane, J. L. Piatek, S. W. Ruff, and W. L. Stefanov (2000b), A thermal emission spectral library of rock-forming minerals, J. Geophys. Res., 105, 9735-9739.

Christensen, P. R., et al. (2001a), Mars Global Surveyor Thermal Emission Spectrometer experiment: Investigation description and surface science results, J. Geophys. Res., 106, 23,823-23,871.

Christensen, P. R., R. V. Morris, M. D. Lane, J. L. Bandfield, and M. C. Malin (2001b), Global mapping of Martian hematite mineral deposits: Remnants of water-driven processes on early Mars, J. Geophys. Res. 106, 23,873-23,885

Christensen, P. R., et al. (2004), Mineralogy at Meridiani Planum from the Mini-TES experiment on the Opportunity rover, Science, 306, 1733 1739

Clancy, R. T., S. W. Lee, G. R. Gladstone, W. W. McMillan, and T. L. Roush (1995), A new model for Mars atmospheric dust based upon analysis of ultraviolet through infrared observations from Mariner 9, Viking, and PHOBOS, J. Geophys. Res., 100, 5251-5263.

Clark, B. C. (1993), Geochemical components in Martian soil, Geochim. Cosmochim. Acta, 57, 4575-4581.

Clark, B. C., and D. C. Van Hart (1981), The salts of Mars, Icarus, 45, $370-378$

Clark, B. C., A. K. Baird, R. J. Weldon, D. M. Tsusaki, L. Schnabel, and M. P. Candelaria (1982), Chemical composition of Martian fines, J. Geophys. Res., 87, 10,059-10,067.

Conrath, B., R. Curran, R. Hanel, V. Kunde, W. Maguire, J. Pearl, J. Pirraglia, and J. Welker (1973), Atmospheric and surface properties of Mars obtained by infrared spectroscopy on Mariner 9, J. Geophys. Res., 78, 4267-4278

Erard, S., J. Mustard, S. Murchie, J.-P. Bibring, P. Cerroni, and A. Coradini (1994), Martian aerosols: Near-infrared spectral properties and effects on the observation of the surface, Icarus, 111, 317-337.

Federova, A. A., E. Lellouch, D. V. Titov, T. De Graauw, and H. Feuchtgruber (2002), Remote sounding of the Martian dust from ISO spectroscopy in the $2.7 \mu \mathrm{m} \mathrm{CO}_{2}$ bands, Planet. Space Sci., 50, 3-9.

Gellert, R., et al. (2004), Chemistry of rocks and soils in Gusev Crater from the alpha particle X-ray spectrometer, Science, 305, 829-832.

Gendrin, A., et al. (2005), Sulfates in Martian layered terrains: The OMEGA/Mars Express view, Science, 307, 1587-1591.

Glotch, T. D., and P. R. Christensen (2005), Geologic and mineralogic mapping of Aram Chaos: Evidence for a water-rich history, J. Geophys Res., 110, E09006, doi:10.1029/2004JE002389.

Glotch, T. D., R. V. Morris, P. R. Christensen, and T. G. Sharp (2004), Effect of precursor mineralogy on the thermal infrared emission spectra of hematite: Application to Martian hematite mineralization, J. Geophys. Res., 109, E07003, doi:10.1029/2003JE002224

Goetz, W., et al. (2005), Indication of drier periods on Mars from the chemistry and mineralogy of atmospheric dust, Nature, 436, 62-65.

Gooding, J. L. (1992), Soil mineralogy and chemistry on Mars: Possible clues from salts and clays in SNC meteorites, Icarus, 99, 28-41.

Grassi, D., and V. Formisano (2000), IRIS Mariner 9 data revisited: 2 Aerosol dust composition, Planet. Space Sci., 48, 577-598.

Hamilton, V. E. (2000), Thermal infrared emission spectroscopy of the pyroxene mineral series, J. Geophys. Res., 105, 9701-9716.

Hamilton, V. E. (2003), Constraints on the composition and particle size of high albedo regions on Mars, in Sixth International Conference on Mars [CD-ROM], Abstract 3239, Lunar and Planet. Inst., Houston, Tex.

Hamilton, V. E., and P. R. Christensen (2000), Determining the modal mineralogy of mafic and ultramafic igneous rocks using thermal emission spectroscopy, J. Geophys. Res., 105, 9717-9733.

Hamilton, V. E., and R. V. Morris (2003), Thermal emission spectra of altered tephras and constraints on the composition of Martian dust, Lunar Planet. Sci. [CD-ROM], XXXIV, Abstract 1936.

Hamilton, V. E., M. B. Wyatt, H. Y. McSween Jr., and P. R. Christensen (2001), Analysis of terrestrial and Martian volcanic compositions using thermal emission spectroscopy: 2. Application to Martian surface spectra from the Mars Global Surveyor Thermal Emission Spectrometer, J. Geophys. Res., 106(E7), 14,733-14,746.

Hanel, R. A., et al. (1972a), Investigation of the Martian environment by infrared spectroscopy on Mariner 9, Icarus, 17, 423-442.

Hanel, R. A., B. J. Conrath, W. A. Hovis, V. G. Kunde, P. D. Lowman, J. C Pearl, C. Prabhakara, and B. Schlachman (1972b), Infrared spectroscopy experiment on the Mariner 9 mission: Preliminary results, Science, 175 , $305-308$
Hansen, G. B. (2003), Infrared optical constants of Martian dust derived from Martian spectra, in Sixth International Conference on Mars [CD-ROM], Abstract 3194, Lunar and Planet. Inst., Houston, Tex.

Hapke, B. (1993), Combined theory of reflectance and emittance spectroscopy, in Remote Geochemical Analysis: Elemental and Mineralogical Composition, edited by C. M. Pieters and P. A. J. Englert, chap. 32, pp. 31-42, Cambridge Univ. Press, New York.

Hapke, B. (1996a), Applications of an energy transfer model to three problems in planetary regoliths: The solid-state greenhouse, thermal beaming, and emittance spectra, J. Geophys. Res., 101, 16,833-16,840.

Hapke, B. (1996b), A model of radiative and conductive energy transfer in planetary regoliths, J. Geophys. Res., 101, 16,817-16,831.

Houck, J. R., J. B. Pollack, C. Sagan, D. Schaack, and J. A. Decker Jr. (1973), High altitude infrared spectroscopic evidence for bound water on Mars, Icarus, 18, 470-480.

Hugeunin, R. L. (1987), The silicate component of Martian dust, Icarus, 70, $162-188$.

Hunt, G. R., L. M. Logan, and J. W. Salisbury (1973), Mars: Components of infrared spectra and the composition of the dust cloud, Icarus, 18, $459-469$

Kirkland, L. E., and K. C. Herr (2000), Spectral anomalies in the 11 and 12 $\mu \mathrm{m}$ region from the Mariner Mars 7 infrared spectrometer, J. Geophys. Res., 105, 22,507-22,515.

Kirkland, L. E., K. C. Herr, and P. B. Forney (1999), Comparison of 1969 IRS and IRIS spectra to TES, paper presented at Fifth International Mars Science Conference, Calif. Inst. of Technol., Pasadena, Calif.

Klingelhöfer, G. (2004), Jarosite and hematite at Meridani Planum from Opportunity's Mössbauer spectrometer, Science, 306, 1740-1745.

Koeppen, W. C., and V. E. Hamilton (2005), Discrimination of glass and phyllosilicate minerals in thermal infrared data, J. Geophys. Res., 110, E08006, doi:10.1029/2005JE002474

Lane, M. D., M. D. Dyar, and J. L. Bishop (2004), Spectroscopic evidence for hydrous iron sulfate in the Martian soil, Geophys. Res. Lett., 31, L19702, doi:10.1029/2004GL021231.

Larsen, K. W., R. E. Arvidson, B. L. Jolliff, and B. C. Clark (2000), Correspondence and least squares analyses of soil and rock compositions for the Viking Lander 1 and Pathfinder landing sites, J. Geophys. Res., $105,29,207-29,222$.

Lellouch, E., T. Encrenaza, T. de Graauw, S. Erard, P. Morris, J. Crovisier, H. Feuchtgruber, T. Girard, and M. Burgdorf (2000), The 2.4-45 $\mu \mathrm{m}$ spectrum of Mars observed with the infrared space observatory, Planet. Space Sci., 48, 1393-1405.

Lyon, R. J. P., W. M. Tuddenham, and C. S. Thompson (1959), Quantitative mineralogy in 30 minutes, Econ. Geol., 54, 1047-1055.

Madsen, M. B., S. F. Hviid, H. P. Gunnlaugsson, J. M. Knudsen, W. Goetz, C. T. Pedersen, A. R. Dinesen, C. T. Mogensen, and M. Olsen (1999), The magnetic properties experiment on Mars Pathfinder, J. Geophys. Res., 104, 8761-8779.

McLennan, S. M. (2000), Chemical composition of Martian soil and rocks: Complex mixing and sedimentary transport, Geophys. Res. Lett., 27, $1335-1338$.

McSween, H. Y., Jr., and K. Keil (2000), Mixing relationships in the Martian regolith and the composition of globally homogeneous dust, Geochim. Cosmochim. Acta, 64, 2155-2166.

McSween, H. Y., Jr., and A. H. Treiman (1998), Martian samples, in Planetary Materials, Rev. Mineral., vol. 36, edited by J. J. Papike, pp. 6-1 to 6-53, Mineral. Soc. of Am., Washington, D. C.

McSween, H. Y., Jr., et al. (2004), Basaltic rocks analyzed by the Spirit rover in Gusev crater, Science, 305, 842-845.

Moroz, V. I., E. V. Petrova, L. V. Ksanfomaliti, L. Espozito, and J.-P. Bibring (1990), Aerosol characteristics in the Martian atmosphere according to data from the KRFM experiment, Kosm. Issled., 28, 936-942.

Morris, R. V., and G. Klingelhöfer (2005), Moessbauer mineralogical evidence for water- and sulfate-bearing phases at Gusev crater and Meridiani Planum: The view after one year, Eos Trans. AGU, 86(18), Jt. Assem. Suppl., Abstract P31A-05.

Morris, R. V., D. G. Agresti, H. V. Lauer Jr., J. A. Newcomb, T. D. Shelfer, and A. V. Murali (1989), Evidence for pigmentary hematite on Mars based on optical, magnetic, and Mössbauer studies of superparamagnetic (nanocrystalline) hematite, J. Geophys. Res., 94, 2760-2778.

Morris, R. V., J. L. Gooding, H. V. Lauer Jr., and R. B. Singer (1990), Origins of Marslike spectral and magnetic properties of a Hawaiian palagonitic soil, J. Geophys. Res., 95, 14,427-14,434.

Morris, R. V., et al. (2000), Mineralogy, composition, and alteration of Mars Pathfinder rocks and soils: Evidence from multispectral, elemental, and magnetic data on terrestrial analogue, SNC meteorite, and Pathfinder samples, J. Geophys. Res., 105, 1757-1817.

Murchie, S., J. Mustard, J. Bishop, J. Head, C. Pieters, and S. Erard (1993), Spatial variations in the spectral properties of bright regions on Mars, Icarus, $105,454-468$. 
Omori, K. (1967), Infrared study of mechanical mixtures of quartz, orthoclase, and oligoclase from 11 to 25 microns, Mineral. J., 5, 169-179.

Pleskot, L. K., and E. D. Miner (1981), Time variability of Martian bolometric albedo, Icarus, 45, 179-201.

Pollack, J. B., T. L. Roush, F. Witteborn, J. Bregman, D. Wooden, C. Stoker, O. B. Toon, D. Rank, B. Dalton, and R. Freedman (1990), Therma emission spectra of Mars $(5.4-10.5 \mu \mathrm{m})$ : Evidence for sulfates, carbonates, and hydrates, J. Geophys. Res., 95, 14,595-14,627.

Ramsey, M. S., and P. R. Christensen (1998), Mineral abundance determination: Quantitative deconvolution of thermal emission spectra, J. Geophys. Res., 103, 577-596.

Rieder, R., et al. (2004), Chemistry of rocks and soils at Meridiani Planum from the alpha particle X-ray spectrometer, Science, 306, 1746-1749.

Roush, T. L., J. B. Pollack, and J. Orenberg (1991), Derivation of midinfrared $(5-25 \mu \mathrm{m})$ optical constants of some silicates and palagonite, Icarus, 94, 191-208.

Ruff, S. W. (2004), Spectral evidence for zeolite in the dust on Mars, Icarus, 168, 131-143.

Salisbury, J. W., L. S. Walter, N. Vergo, and D. M. D'Aria (1991), Infrared (2.1-25 $\mu \mathrm{m})$ Spectra of Minerals, 267 pp., Johns Hopkins Univ. Press, Baltimore, Md

Smith, M. D., J. L. Bandfield, and P. R. Christensen (2000), Separation of atmospheric and surface spectral features in Mars Global Surveyor Thermal Emission Spectrometer (TES) spectra, J. Geophys. Res., 105, 95899607

Snook, K. J. (1999), Infrared optical properties and radiative heating effects of dust suspended in the Mars atmosphere, Ph.D. thesis, Stanford Univ. Stanford, Calif.

Snook, K. J. (2002), Properties of suspended Martian dust using MGS-TES data, Lunar Planet. Sci. [CD-ROM], XXXIII, abstract 1600.
Toon, O. B., J. B. Pollack, and C. Sagan (1977), Physical properties of the particles composing the Martian dust storm of 1971-1972, Icarus, 30, $663-696$

Toulmin, P. III, A. K. Baird, B. C. Clark, K. Keil, J. H. J. Rose, R. P. Christian, P. H. Evans, and W. C. Kelliher (1977), Geochemical and mineralogical interpretation of the Viking inorganic chemical results, J. Geophys. Res., 82, 4625-4634.

Wänke, H., J. Brückner, G. Dreibus, R. Rieder, and I. Ryabchikov (2001), Chemical composition of rocks and soils at the Pathfinder site, Space Sci. Rev. 96, 317-330.

Wolff, M. J., and R. T. Clancy (2003), Constraints on the size of Martian aerosols from Thermal Emission Spectrometer observations, J. Geophys. Res., 108(E9), 5097, doi:10.1029/2003JE002057.

Wyatt, M. B., and H. Y. McSween Jr. (2002), Spectral evidence for weathered basalt as an alternative to andesite in the northern lowlands of Mars, Nature, 417, 263-266.

Yen, A. S., B. C. Murray, and G. R. Rossman (1998), Water content of the Martian soil: Laboratory simulations of reflectance spectra, J. Geophys. Res., 103, 11,125-11,134.

Yen, A. S., et al. (2005), An integrated view of the chemistry and mineralogy of Martian soils, Nature, 436, 49-54.

V. E. Hamilton, Hawaii Institute of Geophysics and Planetology, University of Hawaii, 1680 East-West Road, Honolulu, HI 96822, USA. (hamilton@higp.hawaii.edu)

B. Hapke, Department of Geology and Planetary Sciences, University of Pittsburgh, Pittsburgh, PA 15260, USA.

H. Y. McSween Jr., Department of Earth and Planetary Sciences, University of Tennessee, Knoxville, TN 37996-1410, USA. 